\title{
Examination of wind speed thresholds for vorticity-driven lateral fire spread
}

\author{
J.J. Sharples ${ }^{\text {a }}$, C.C. Simpson ${ }^{\text {a }}$, J.P. Evans ${ }^{\text {b }}$, \\ ${ }^{a}$ Applied and Industrial Mathematics Research Group, School of Physical, Environmental and Mathematical \\ Sciences, UNSW Canberra, Australia. \\ ${ }^{\mathrm{b}}$ Climate Change Research Centre, Faculty of Science, University of New South Wales, Sydney, Australia. \\ Email: j.sharples@adfa.edu.au
}

\begin{abstract}
Recent work has demonstrated that under conditions of extreme fire weather, bushfires burning in rugged terrain can exhibit highly atypical patterns of propagation, which can have a dramatic effect on subsequent fire development. In particular, wildfires have been observed to spread laterally across steep, lee-facing slopes in a process that has been termed 'fire channelling'. Fire channelling, in turn, has been associated with serious escalation in fire activity and the development of pyrocumulonimbus storms. Coupled fire-atmosphere modelling using large eddy simulation has indicated that the fire channelling phenomenon occurs in response to fire-induced vorticity on the fire's flanks in the immediate lee of a ridge line. In this paper we extend previous modelling, using the WRF-Fire coupled fire-atmosphere model, to specifically consider the effect of wind speed in generating the fire-induced vorticity necessary to drive the lateral spread associated with fire channelling.
\end{abstract}

We examine the behaviour of simulated fires on leeward slopes under different wind speed regimes, which are characterised in terms of a reference wind speed $U_{0}$. The topography is taken to be an idealised triangular mountain with a north-south oriented ridge line. The windward and leeward slopes are taken to be $20^{\circ}$ and $35^{\circ}$, respectively, and the height of the mountain is approximately $1 \mathrm{~km}$. Initial and boundary conditions are taken in the form of a vertical wind profile that has a uniform horizontal (westerly) wind field of constant speed $U_{0}$ at $200 \mathrm{~m}$ or above, and decays quadratically for heights below $200 \mathrm{~m}$, to zero at the surface level, maintaining its westerly direction throughout. Moisture is assumed to be absent throughout the profile and potential temperature is assumed to be a constant $300 \mathrm{~K}$. The reference wind speed $U_{0}$ is prescribed values of $0,2.5,5,7.5,10$ and $15 \mathrm{~m} \mathrm{~s}^{-1}$.

The simulated fire spread under each of the wind speed regimes was examined for evidence of the occurrence of rapid lateral spread across the leeward slope. Under the two lowest wind speed regimes the fire did not exhibit any atypical lateral spread, in stark contrast to the two highest wind speed regimes, in which the simulated fires readily exhibited significantly faster lateral spread. The results suggest the existence of a threshold wind speed, below which the prevailing winds are too weak to drive the vorticity-generating interaction between the wind, the terrain and the fire's plume, so that no atypical lateral spread occurs. The model simulations further suggest that this threshold occurs for wind regimes characterised by $U_{0} \approx 5 \mathrm{~m} \mathrm{~s}^{-1}$.

The modelling results are also discussed in connection with some recent laboratory-scale fires examining the same effect. The fire behaviour in both cases was found to be qualitatively consistent, though issues surrounding the transferability of the results across the different spatial scales involved prevented a more quantitative comparison.

The simulated behaviour of fires on leeward slopes, and the transistion in fire propagation that can occur when prevailing winds are sufficiently strong, highlight the inherent dangers associated with firefighting in rugged terrain. The propensity for dynamic interactions to produce erratic and dangerous fire behaviour in such environments has strong implications for firefighter and community safety. At the very least the research findings provide additional support for the use of well-briefed observers in firefighting operations in complex topography.

Keywords: Wildfire simulation, fire channelling, wind-terrain-fire interaction 


\section{INTRODUCTION}

Dynamic escalation of wildland fires into large conflagrations represents a significant challenge to the management of fires in the landscape. Multi-scale interactions between a fire and the local environment, which includes fuels, weather and topography, can produce highly complex fire behaviour that is currently beyond the predictive power of operational fire spread models. Understanding the physical processes that underpin these complex modes of fire propagation is therefore a key step in improving the planning, preparedness, response and recovery surrounding the incidence of extreme bushfires.

Recent research into the behaviour of wildfires has identified a number of dynamic modes of fire propagation. These modes of fire spread are referred to as dynamic because they are manifestly at odds with quasi-steady fire spread, whereby a fire will spread at an approximately constant rate given uniform environmental conditions. Viegas (2005) and Dold and Zinoviev (2009) examined the ability of a fire to exhibit exponentially increasing rates of spread up steep slopes and canyons, while Viegas et al. (2012) discussed the abrupt increases in rate of spread that can occur when two lines of fires intersect at some oblique angle.

Another form of dynamic fire propagation was identified by Sharples et al. (2012) in connection with the 2003 Canberra bushfires. This phenomenon, which they referred to as fire channelling, involved the rapid lateral propagation of a fire across a lee-facing slope in a direction approximately perpendicular to the prevailing wind direction. Sharples et al. (2012) conjectured that the lateral spread was due to an interaction between the wind, the terrain and an active fire.

Simpson et al. (2013) used a coupled fire-atmosphere model to numerically simulate the fire channelling phenomenon in the case of a fire burning on the lee slope of an idealised triangular mountain, with ridge line oriented perpendicular to the prevailing wind. In this study, a reference wind speed of $20 \mathrm{~m} \mathrm{~s}^{-1}$ was used to investigate the interaction of the terrain modified flow with the fire plume. It was found that this interaction resulted in the intermittent generation of vertical vorticity, which drove the fire laterally across the top of the slope in the immediate lee of the ridge line. As such, Simpson et al. (2013) permitted the characterisation of fire channelling as vorticity-driven lateral spread.

Farinha (2011) conducted a number of combustion tunnel experiments to examine the behaviour of fires burning on the leeward slope of a small triangular ridge. He found that in the absence of wind the fires burn uniformly across the slope at a distinctly quasi-steady rate of spread. In the presence of combustion tunnel winds of $1.5 \mathrm{~m} \mathrm{~s}^{-1}$ or greater Farinha (2011) found that the fire spread rapidly across the top of the leeward slope at a significantly accelerated rate. The rate of lateral spread varied with the speed of the wind, with the greater rates of lateral spread coinciding with the fastest wind speeds.

In the present paper, the study of Simpson et al. (2013) is extended to examine the effect of variation in wind speed on the occurrence of vorticity-driven lateral spread across a lee-facing slope, as was addressed experimentally by Farinha (2011). To do this the reference wind speed is varied while retaining the same basic structure of the initial wind profile and the topography used by Simpson et al. (2013). The aim of the present study is to ascertain if there is a wind speed threshold, below which vorticity-driven lateral spread does not occur. The 'deep flaming' associated with the fire channelling phenomenon (Sharples et al., 2012) can act as a strong source of pyro-convection, and so systematically establishing the environmental thresholds relating to fire channelling will provide improved guidance for predicting the onset of extreme pyro-convection and blow-up fire behaviour. As such, the present study has direct implications for firefighter and community safety.

\section{METHODS}

Version 3.5 of the Weather Research and Forecasting (WRF) model (Skamarock et al., 2008) is used in a large eddy simulation (LES) configuration (Moeng et al., 2007) and coupled to the SFIRE fire spread model (Mandel et al., 2011). This coupled atmosphere-fire numerical modelling system, commonly referred to as WRF-Fire, is suited to modelling turbulent atmosphere-fire interactions on length scales of tens of metres to kilometres. The WRF-LES model explicitly resolves grid-scale atmospheric eddies, whereas the effects of subgrid-scale motions are modelled using a subfilter-scale stress model. WRF utilises fully compressible nonhyrdostatic equations and has a mass-based terrain-following coordinate system. The WRF-LES model domain has dimensions of $15 \mathrm{~km} \times 5 \mathrm{~km} \times 5 \mathrm{~km}$ with open radiative boundaries. The horizontal and vertical grid spacing are $50 \mathrm{~m}$, although due to the use of mass levels the vertical grid spacing is not constant. A triangular mountain is located within the model domain, as shown in Figure 1, with its ridge line oriented perpendicular to the prevailing wind. The windward and leeward slope angles are $20^{\circ}$ and $35^{\circ}$, respectively, and the mountain height is $1 \mathrm{~km}$. The initial and lateral boundary conditions are specified using a 1D sounding, 


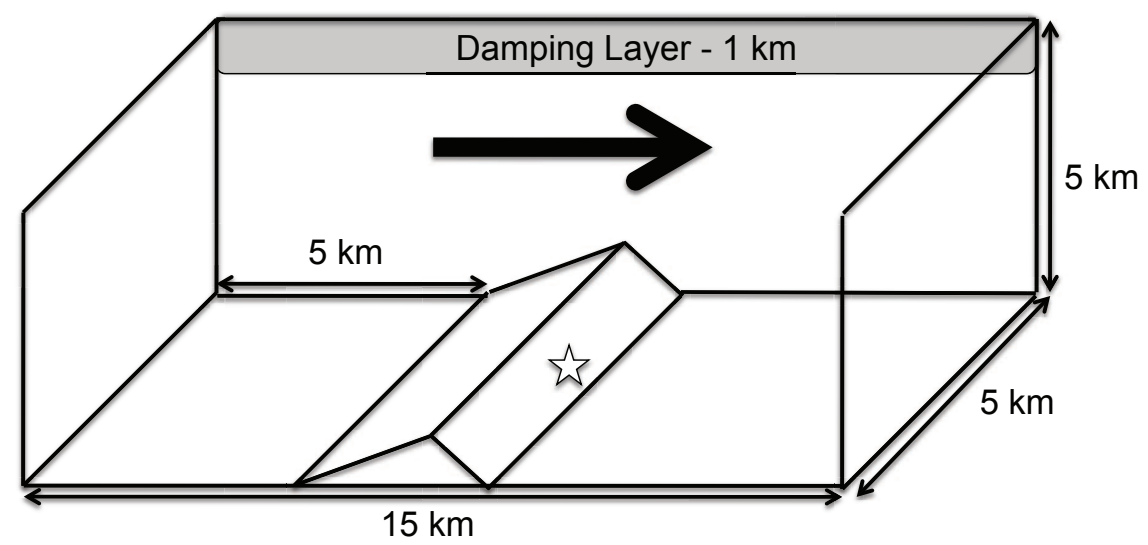

Figure 1. Model domain showing the triangular mountain with its ridge line oriented perpendicular to the input wind field. The windward slope is inclined at $20^{\circ}$ and the leeward slope is inclined at $35^{\circ}$. The star on the leeward slope indicates the approximate location of the igntion line used in the simulations.

with a vapor mixing ratio of zero, a constant potential temperature of $300 \mathrm{~K}$ and a wind profile given by $\mathbf{U}_{0}$, which expressed as a function of the Cartesian coordinates $(x, y, z)$, is

$$
\mathbf{U}_{0}(x, y, z)=U_{0} P(z) \hat{\mathbf{x}}
$$

Here $U_{0}$ denotes the reference wind speed - the main variable of interest in this study, and $\hat{\mathbf{x}}$ denotes the unit vector in the $x$-direction (which coincides with east). The function $P(z)$ in equation (1) prescribes the vertical structure of the initial wind field profile, and is defined as:

$$
P(z)=\left\{\begin{array}{cc}
\left(\frac{z}{200}\right)^{2} & z \leq 200 \\
1 & z>200
\end{array}\right.
$$

We use a quadratic profile here, rather than the usual logarithmic profile, for the sake of simplicity and, and more importantly, so that our results are directly comparable with those of Simpson et al. (2013).

WRF offers either a physical (not used) or free-slip (used) bottom boundary condition. Since the lowest model level is still above the actual ground level, we don't have a completely zero wind speed on any WRF model level. However, it should be noted that a fuel-dependent roughness length is used in vertically interpolating the wind speeds down to the mid-flame height, so even though we use a free-slip in WRF its not like we're not considering surface roughness).

The WRF-LES model is used in an idealised configuration and there is no modelling of the microphysics, radiation physics, cumulus physics and the surface and planetary boundary layers. However, it should be noted that a fuel-dependent roughness length is used in vertically interpolating the wind speeds down to the midflame height. Diffusion in physical space is calculated using the velocity stress tensor and the eddy viscosities are calculated using a 3D prognostic 1.5-order turbulence closure scheme. A Rayleigh damping layer in the top $1 \mathrm{~km}$ is used to prevent reflection of the pyro-convective plume from the model top. The primary model time integration is performed using a third-order Runge-Kutta scheme and a secondary time step is used to handle acoustic waves. The primary and secondary model time steps are $0.1 \mathrm{~s}$ and $0.0125 \mathrm{~s}$, respectively.

A line fire is ignited in the SFIRE model near the base of the leeward slope (Fig. 1), after a WRF-LES spin-up period of $20 \mathrm{~min}$. The line fire is $100 \mathrm{~m}$ wide in the $x$-direction and is ignited asymmetrically from south to north along a $400 \mathrm{~m}$ line centred on the $y$-axis. The subsequent fire spread is modelled on a $10 \mathrm{~m} \times 10 \mathrm{~m}$ horizontal grid as a temporally evolving fire perimeter using a level set function. The spatially and temporally varying fire spread rate, $S$, is calculated using the Rothermel equation (Rothermel, 1972):

$$
S=R_{0}\left(1+\phi_{W}+\phi_{S}\right)
$$


The base rate of spread, $R_{0}$, is dependent on the parameterised fuel properties. The slope correction factor, $\phi_{S}$, is calculated using the local terrain in SFIRE. The wind correction factor, $\phi_{W}$, is calculated from the WRF modelled wind speeds, which are vertically interpolated to an estimated mid-flame height. The "heavy logging slash" Anderson fuel category (Anderson, 1982) is used to initialise the fuel conditions homogeneously across the SFIRE model domain. The parameterised fuel properties include the initial mass loading, fuel depth, surface area to volume ratio, moisture content of extinction and rate of mass loss following ignition.

The two-way atmosphere-fire coupling between SFIRE and WRF-LES is achieved through the release of latent and sensible heat from the modelled fire. For $1 \mathrm{~kg}$ of fuel combusted in SFIRE there is $17.43 \mathrm{MJ}$ of sensible heat released into the WRF-LES model, which is about a factor of ten higher than the latent heat released for the fuel type used. These heat fluxes are distributed throughout the WRF-LES vertical levels using an exponential decay function and allows SFIRE to directly modify the atmospheric conditions surrounding the modelled fire. The two-way coupling in WRF-Fire allows it to directly model atmosphere-terrain-fire interactions down to length scales of tens to hundreds of metres.
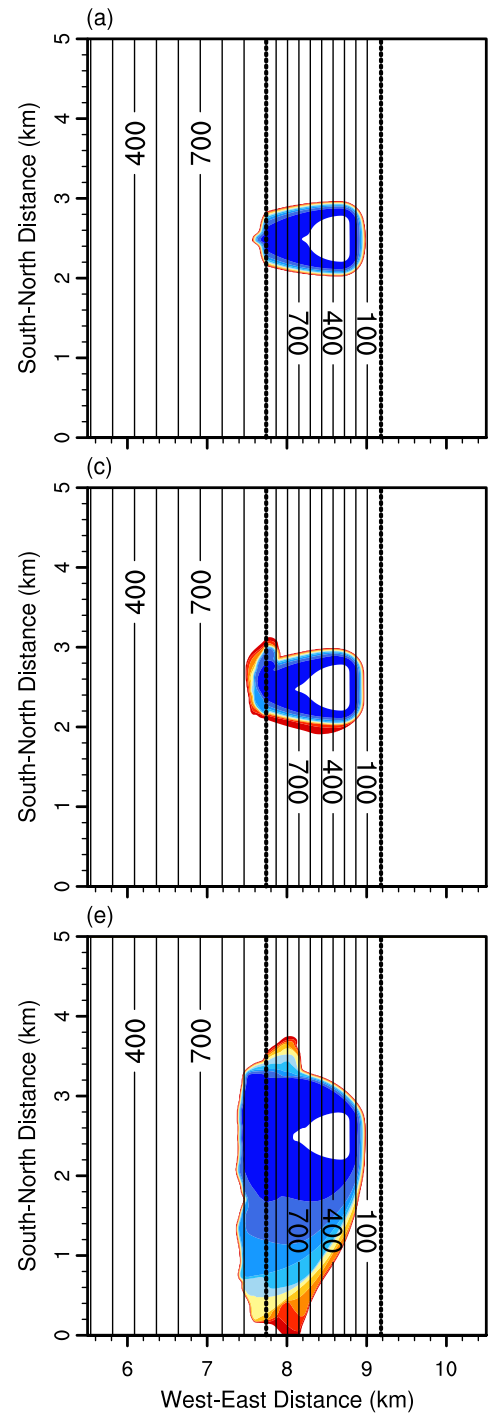

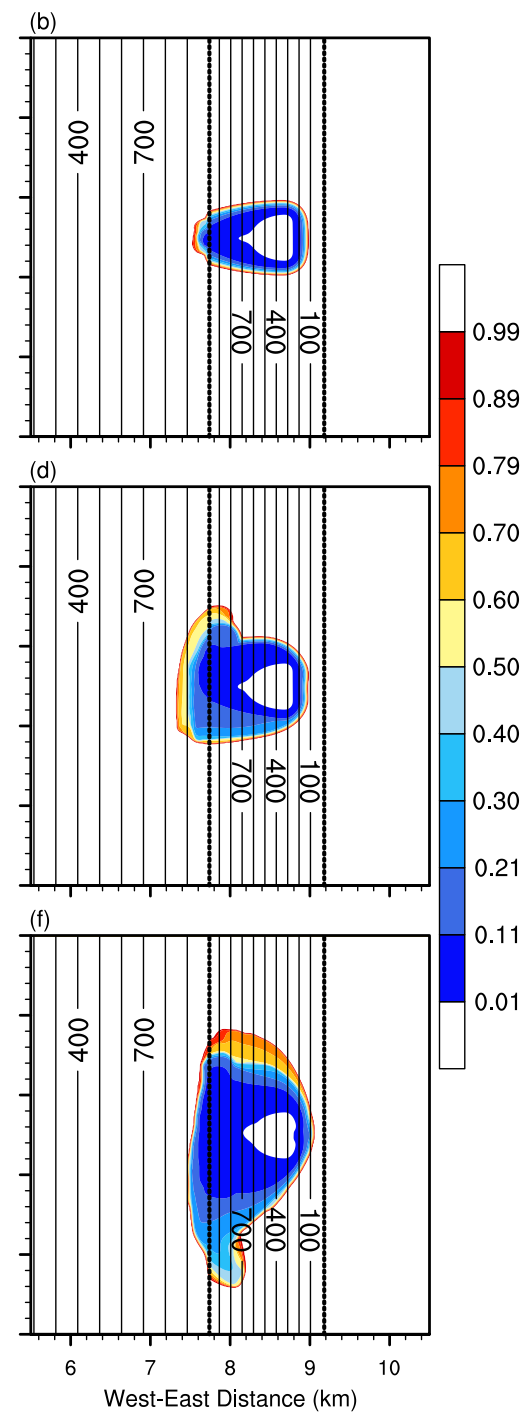

Figure 2. Fuel fraction after 120 minutes of elapsed time, simulated using different reference winds speeds: (a) $U_{0}=0 \mathrm{~m} \mathrm{~s}^{-1}$; (b) $U_{0}=2.5 \mathrm{~m} \mathrm{~s}^{-1}$; (c) $U_{0}=5 \mathrm{~m} \mathrm{~s}^{-1}$; (d) $U_{0}=7.5 \mathrm{~m} \mathrm{~s}^{-1}$; (e) $U_{0}=10 \mathrm{~m} \mathrm{~s}^{-1}$; (f) $U_{0}=15 \mathrm{~m} \mathrm{~s}^{-1}$. 


\section{RESULTS}

The simulations were conducted using values of the reference wind speed of $U_{0}=0.0,2.5,5.0,7.5,10.0$ and $15.0 \mathrm{~m} \mathrm{~s}^{-1}$. In each of these cases the model output was examined for instances of significant lateral spread (i.e. spread along the north-south direction). This was accomplished by scrutinising the patterns of fire spread as indicated by changes in the fuel fraction, which varies between 1 (unburnt fuel) and 0 (fuel totally consumed). The characteristics of the plume behaviour under the different reference wind speeds were also examined.

\subsection{Lateral spread characteristics}

The fuel fraction remaining 120 minutes after ignition is displayed for each of these cases in Figure 2. Not surprisingly, the $U_{0}=0 \mathrm{~m} \mathrm{~s}^{-1}$ fire spread simulation did not exhibit any atypical lateral spread. Indeed, the fuel fraction field displayed in Figure 2a indicates that the fire simply spread up the $35^{\circ}$ slope and then began to spread back down the $20^{\circ}$ slope with a pattern of fire propgation that was distinctly towards the west. The lateral spread to the north and south in this simulation was much slower in comparison and did not indicate any occurrence of dynamic behaviour.

Similarly, for the $U_{0}=2.5 \mathrm{~m} \mathrm{~s}^{-1}$ case, the simulation did not give any indication of rapid lateral spread to the north or south (Fig. 2b). In the $U_{0}=5 \mathrm{~m} \mathrm{~s}^{-1}$ case, the simulated fire spread exhibited a small lateral bulge towards the north 120 minutes after ignition (Fig. 2c). The behaviour observed in this case is similar to that noted by Simpson et al. (2013) and is consistent with the lateral spread associated with the fire channelling phenomenon.

The remaining Figures $2 \mathrm{~d}, 2 \mathrm{e}$ and $2 \mathrm{f}$ indicate that atypical lateral spread occurred for all of the $U_{0}>5 \mathrm{~m}$ $\mathrm{s}^{-1}$ cases. In particular, the $U_{0}=10$ and $15 \mathrm{~m} \mathrm{~s}^{-1}$ cases exhibit intermittent lateral spread, first towards the north and then later towards the south at a much faster rate.

Figure 3 quantifies the lateral spread rate (averaged over 5 minute intervals) for each of the reference wind cases. The $U_{0}=0 \mathrm{~m} \mathrm{~s}^{-1}$ and $U_{0}=2.5 \mathrm{~m} \mathrm{~s}^{-1}$ cases produced near identical quasi-steady lateral spread rates of approximately $0.2 \mathrm{~km} \mathrm{~h}^{-1}$ : the curves in Figure 3 are indistinguishable. The lateral spread rate observed during the $U_{0}=5 \mathrm{~m} \mathrm{~s}^{-1}$ simulation was also of the order of $0.2 \mathrm{~km} \mathrm{~h}^{-1}$, though after 65 minutes some intermittent lateral spread occurred at rates of up to $1.0-1.5 \mathrm{~km} \mathrm{~h}^{-1}$; that is, 5-8 times the lateral rates of spread observed in the two lowest reference wind speed cases. For the simulations with $U_{0}>5 \mathrm{~m} \mathrm{~s}^{-1}$, lateral

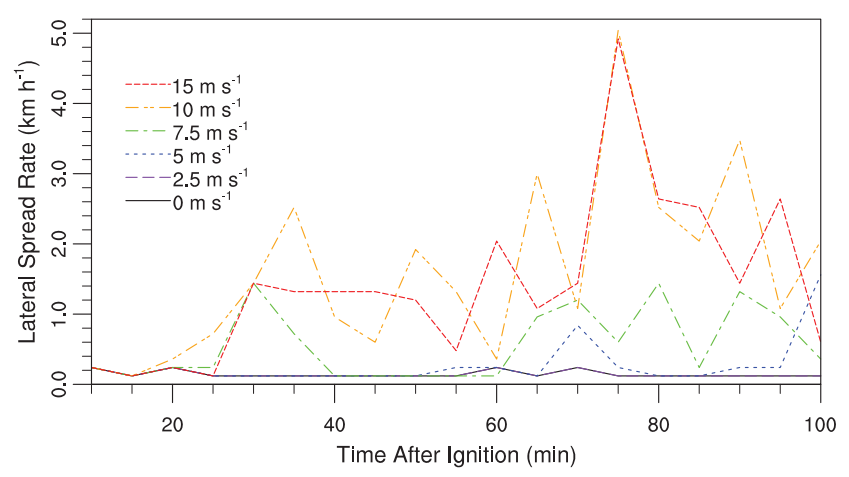

Figure 3. Lateral spread rate for different reference wind speeds.

rates of spread all displayed a marked increase 30-35 minutes after ignition, which corresponds approximately to the time the fire reached the apex of the triangular mountain. At this point in time all of the simulated fires with $U_{0}>5 \mathrm{~m} \mathrm{~s}^{-1}$ displayed lateral rates of spread of about $1.5 \mathrm{~km} \mathrm{~h}^{-1}$. After this point the simulated fires spread laterally in an oscillatory manner, with a number of distinct maxima and minima evident in Figure 3 for the $U_{0}>5 \mathrm{~m} \mathrm{~s}^{-1}$ cases. The $U_{0}=10$ and $15 \mathrm{~m} \mathrm{~s}^{-1}$ cases, in particular, spread laterally with an average rate of spread of approximately $2 \mathrm{~km} \mathrm{~h}^{-1}$ and achieved maximum lateral rates of spread of approximately 5 $\mathrm{km} \mathrm{h}^{-1} 75$ minutes after ignition. This means that in the two highest reference wind speed cases, the fires 
exhibited lateral rates of spread that were up to 25 times the quasi-steady lateral spread rates seen in the two lowest reference wind speed cases.

The results suggest that in our experimental setup, there is a threshold between two distinct propagation regimes: one in which the prevailing winds are too weak to drive the vorticity-generating interaction between the wind, the terrain and the fire's plume, so that no atypical lateral spread occurs; and one in which vorticitydriven lateral spread readily occurs and sigificantly exacerbates the fire spread. The model simulations further suggest that this threshold occurs somewhere in the vicinity of the $U_{0}=5 \mathrm{~m} \mathrm{~s}^{-1}$ case.

\subsection{Behaviour of the plume}

Figure 4 shows vertical cross sections of the potential temperature and wind fields, taken through the centre of the triangular mountain parallel to the prevailing wind direction. The cases $U_{0}=0 \mathrm{~m} \mathrm{~s}^{-1}$ and $U_{0}=15 \mathrm{~m}$ $\mathrm{s}^{-1}$ are shown at times when the fire was just reaching the apex of the mountain. In the $U_{0}=0 \mathrm{~m} \mathrm{~s}^{-1}$ case the plume consists of a vertical, and apparently laminar flow (unitl it reaches the damping layer). At the other extreme, the plume in the $U_{0}=15 \mathrm{~m} \mathrm{~s}^{-1}$ case is highly turbulent and leans towards the east. In the lee of the plume the atmosphere is highly turbulent. This turbulence is principally due to the fire, but the atmospheric flow alone is also capable of generating lower-magnitude turbulence (Simpson et al., 2013).

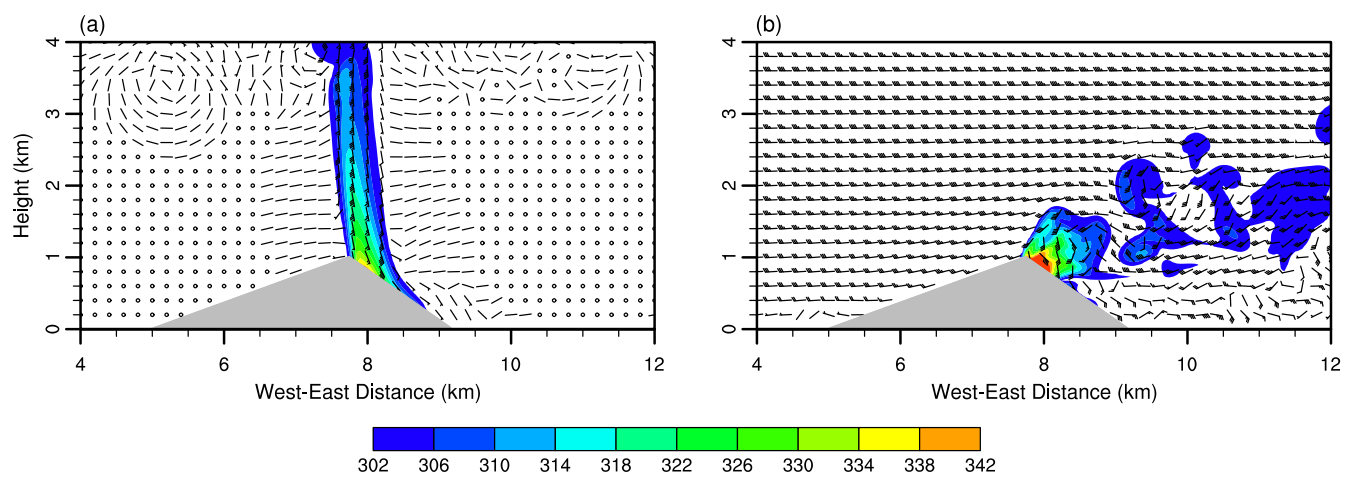

Figure 4. Vertical cross sections of potential temperature $(\mathrm{K})$ and projected wind field (one barb corresponds to 10 knots $=5.14 \mathrm{~m} \mathrm{~s}^{-1}$ ) 40 minutes after ignition. Panel (a) shows the $U_{0}=0 \mathrm{~m} \mathrm{~s}^{-1}$ case, while (b) shows the $U_{0}=15 \mathrm{~m} \mathrm{~s}^{-1}$ case.

\section{DISCUSSION}

The WRF-Fire model was used to numerical simulate the propagation of a fire burning on a leeward slope under different wind speed regimes. The simulations indicated that for lower wind speed regimes; that is, those with a reference speed less than $5 \mathrm{~m} \mathrm{~s}^{-1}$, no vorticity-driven lateral spread occurred. While the $U_{0}=$ $5 \mathrm{~m} \mathrm{~s}^{-1}$ case displayed some lateral spread, the associated rates of spread were not very much above the quasi-steady rates observed in the $U_{0}=0 \mathrm{~m} \mathrm{~s}^{-1}$ and $U_{0}=2.5 \mathrm{~m} \mathrm{~s}^{-1}$ cases, and were significantly less than those observed in the $U_{0}>5 \mathrm{~m} \mathrm{~s}^{-1}$ cases. As such, the $U_{0}=5 \mathrm{~m} \mathrm{~s}^{-1}$ case should perhaps be viewed as the borderline case that defines the wind speed threshold for vorticity-driven lateral spread in our experimental setup. Atypical lateral spread does not occur for wind speeds below $5 \mathrm{~m} \mathrm{~s}^{-1}$ approximately, but will occur once this threshold is exceeded. The cases considered in this study are insufficient to provide any information on how abrupt the transition from one spread regime to the other might be. This issue will be addressed in future work. We can say that in our experimental setup the transition occurs at a reference wind speed somewhere between $2.5 \mathrm{~m} \mathrm{~s}^{-1}$ and $7.5 \mathrm{~m} \mathrm{~s}^{-1}$, with the value most likely in the vicinity of $5 \mathrm{~m} \mathrm{~s}^{-1}$.

The simulated rates of lateral spread observed for the $U_{0}>5 \mathrm{~m} \mathrm{~s}^{-1}$ cases were significantly higher than those observed for the $U_{0} \leq 5 \mathrm{~m} \mathrm{~s}^{-1}$ cases. Indeed, the $U_{0}=10 \mathrm{~m} \mathrm{~s}^{-1}$ and $U_{0}=15 \mathrm{~m} \mathrm{~s}^{-1}$ cases both exhibited rates of spread that were up to 25 times the quasi-steady rates of spread observed for the below threshold cases. While there remain issues in transferring these results to real world cases (e.g. rescaling problems, nonidealised terrain, upstream effects), the very high lateral rates of spread indicated as possible in the simulations would pose a serious risk to any firefighters in areas prone to its occurrence. Indeed, the results suggest that with a slight increase in wind speed firefighters working on leeward slopes could very rapidly find themselves in great peril, when only a short time before their safety had not been in doubt. Moreover, changes in the 
prevailing winds are more difficult to appreciate on leeward slopes, which means that specific 'watchouts' may be difficult to implement without the aid of a dedicated observer to detect changes in wind conditions.

The rates of lateral spread observed in the simulations displayed a distinctly oscillatory or intermittent nature. Indeed, for the two highest reference wind speed cases, the rate of spread oscillated between $0.4 \mathrm{~km} \mathrm{~h}^{-1}$ and $5 \mathrm{~km} \mathrm{~h}^{-1}$. The oscillations appeared quasi-periodic with peaks in the lateral rate of spread occurring approximately 10-15 minutes apart, though this may be an artefact of the 5 minute sampling interval used. The lateral spread also occurred intermittently to the south or to the north. The cause of this oscillatory behaviour is unknown and will be the subject of further investigation.

The results presented above are consistent with the experimental results obtained by Farinha (2011), who considered fires burning on the leeward side of a metre-scale triangular ridge within a combustion tunnel. Farinha (2011) considered wind speeds of $0,1.5,3$ and $4 \mathrm{~m} \mathrm{~s}^{-1}$ and found no lateral spread for the $0 \mathrm{~m}$ $\mathrm{s}^{-1}$ case. For the other cases lateral spread was observed with rates of up to 12 times the quasi-steady rate of spread. The rates of spread observed by Farinha (2011) also displayed an oscillatory nature. Without better knowledge of how to scale between the landscape-scale simulations reported here and the metre-scale combustion tunnel experiments it is difficult to provide further meaningful comparison of the two cases.

Future work will addresss the abruptness of the onset of conditions favouring lateral spread and will extend the analyses to consider the effects of varying the inclination of the slopes making up the triangular mountain, and the effects of varying the angle that the ridge line makes with the prevailing wind direction.

\section{ACKNOWLEDGEMENT}

This work is supported by an Australian Research Council (ARC) Discovery Indigenous Award (IN130100038). J.J. Sharples is also supported by a UNSW Canberra Silver Star Award, while J.P. Evans is also supported by an ARC Future Fellowship (FT110100576). WRF-Fire model runs were performed using the facilities at NCI.

\section{REFERENCES}

Anderson, H. (1982). Aids to determining fuel models for estimating fire behaviour. USDA Forest Service, Intermountain Forest and Range Experiment Station INT-122.

Dold, J. W. and A. Zinoviev (2009). Fire eruption through intensity and spread rate interaction mediated by flow attachment. Combustion Theory and Modelling 13, 763-793.

Farinha, H. A. (2011). Formação de vórtices num incêndio florestal - estudo laboratorial de um vórtice de eixo horizontal e de um tornado de fogo. Master's thesis, Universidade de Coimbra, Portugal.

Mandel, J., J. D. Beezley, and A. K. Kochanski (2011). Coupled atmosphere-wildland fire modeling with WRF 3.3 and SFIRE 2011. Geoscientific Model Development 4, 591-610.

Moeng, C., J. Dudhia, J. Klemp, and P. Sullivan (2007). Examining two-way grid nesting for large eddy simulation of the PBL using the WRF model. Monthly Weather Review 135(6), 2295-2311.

Rothermel, R. (1972). A mathematical model for predicting fire spread in wildland fuels, Volume 115. Intermountain Forest \& Range Experiment Station, Forest Service, US Department of Agriculture.

Sharples, J., R. McRae, and S. Wilkes (2012). Wind-terrain effects on the propagation of large wildfires in rugged terrain: fire channelling. International Journal of Wildland Fire 21, 599-614.

Simpson, C., J. Sharples, J. Evans, and M. McCabe (2013). Large eddy simulation of atypical wildland fire spread on leeward slopes. International Journal of Wildland Fire 22, 282-296.

Skamarock, W. C., J. B. Klemp, J. Dudhia, D. O. Gill, D. M. Barker, M. G. Duda, X.-Y. Huang, W. Wang, and J. G. Powers (2008). A Description of the Advanced Research WRF Version 3 (NCAR Technical Note 475 ed.). Available at: http://www.mmm.ucar.edu/wrf/users/docs/.

Viegas, D. (2005). A mathematical model for forest fires blow-up. Combustion Science and Technology 177, 27-51.

Viegas, D., J. Raposo, D. Davim, and C. Rossa (2012). Study of the jump fire produced by the interaction of two oblique fire fronts. Part 1: Analytical model and validation with no-slope laboratory experiments. International Journal of Wildland Fire 21, 843-856. 